\title{
On Natural and Artificial Intelligence
}

\author{
Luis F. Copertari \\ Computer Engineering Program, Autonomous University of Zacatecas (UAZ), Zacatecas, México \\ Email: copertari@yahoo.com
}

How to cite this paper: Copertari, L.F. (2019) On Natural and Artificial Intelligence. Open Access Library Journal, 6: e5221.

https://doi.org/10.4236/oalib.1105221

Received: February 3, 2019

Accepted: February 25, 2019

Published: February 28, 2019

Copyright $\odot 2019$ by author(s) and Open Access Library Inc.

This work is licensed under the Creative Commons Attribution International License (CC BY 4.0).

http://creativecommons.org/licenses/by/4.0/

(c) (i) Open Access

\begin{abstract}
The current state of the art in knowledge and technology concerning natural and artificial intelligence is innovatively discussed here. The paper goes from concepts of natural intelligence to ideas about the possible nature and future of artificial intelligence. The ideas presented are based both on common sense and scientific research. I dare speculate on the requirements for a strong artificial intelligence to emerge.
\end{abstract}

\section{Subject Areas}

Intelligence, Natural, Artificial, Human, Machine

\section{Keywords}

Anthropology, Information Science

\section{Introduction}

We all feel alone. And the truth is that we really are alone. We are trapped inside our minds and we their prisoners. Why is that so? Because our thoughts are imprisoned in our minds. What are thought made of? Thoughts are the result of our interaction with the world around us through our senses [1]. We have five senses: vision, audition, touch, smell and taste plus a sixth sense of body position located inside our ears. Thus, thoughts start forming from the moment we are born (and even during gestation) as we perceive the world around us. What we see, hear, touch, smell and taste gets intertwined in our minds in the form of images, sounds, sensations, smells and tastes and, as the child grows, they get associated to words, phrases and text, just as memories (sometimes distorted) of moments lived.

The problem is that one second of thinking contains a huge amount of information. Normally, it is an association of images, sounds, sensations and possibly also smells and tastes. A whole book would be required to fully express one 
second of thinking. Thus, how can we convey the complexity of one second of thinking with just one word or even one image? This is the problem of the bandwidth of thought with respect to what can be expressed in one second using any of the five senses.

The bandwidth of thought is much higher than the bandwidth (amount of information transferred per time unit) of any specific sense. The three most important senses are, in this particular order, vision, audition and touch. Touch can transmit much more information than eyes or ears. In fact, eyes only transmit the equivalent of 7 images with very low resolution in 7 different channels of what is at the focus (center) of vision [2]. Consequently, more than seeing the world around us we construct it in our mind as we move the focus of attention of our eyes. We see, then, what we want or expect to see more than what is really there. We also hear in a very limited bandwidth (between 20 and 20,000 hertz). However, what we perceive trough touch contains much more information, including information associated to our sexual organs. It is possible that precisely because of that something as complex as love is linked to the touch throughout all of our body. And romanticism tends to associate the ability to intertwine words related to abstract concepts and images typically associated to romantic thinking.

\section{The Nature of the Human Sense of Self}

Our thoughts change from moment to moment, in the same way the water of a river is always flowing, so that there will never be the same water passing by. However, the river is the same. If our thoughts are constantly flowing, what is it that makes us believe we are the same person, despite the fact that we are constantly changing, both physically and mentally?

Antonio Damasio addresses this question in a TED conference [3] and throughout all of his research [4]-[23]. Observe Figure 1. There is a lateral image of the human brain and a zoom to the base of the spinal cord, the medulla, pons and tectum (colliculi). The pons and the midbrain (in green or light gray) is associated to our ability to move. If this part is damaged, without losing our sense of self, we are left isolated from the rest of the world. We feel and think, we are conscious, but we cannot express ourselves in this regard. This section of the medulla is quite probably the part that is blocked while we sleep and dream, so that we do not act upon our dreams, which would be very dangerous. However, the tectum (in red or dark grey) is connected to the interior of our bodies, to the hormone levels, to the body rhythms, to breading, to heart beats and the homeostatic maintenance of our corporal metabolism. Certainly, these mechanisms are very stable and vary very little. This is the part of the brain that is connected, both physically and mentally, to the interior of our body. Due to the constancy of these parameters, it is precisely the part of our being that gives us a sense of continuity and does not change. It is then, the part of the brain that gives us the idea, the phenomenon, of self, that we continue to be ourselves. It is 


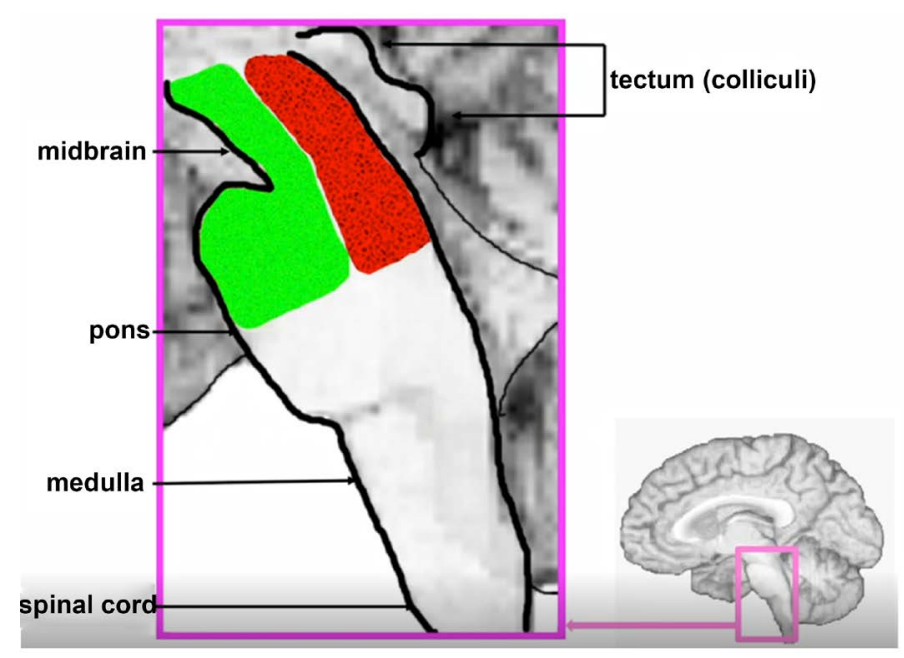

Figure 1. The location of the self in the human brain.

the part of us that does not change, which gives us the idea of continuity of one being. It is the basis for the construction of the self.

\section{The Three Components of the Human Mind}

When we talk about the mind, and more specifically the psyche, psychoanalysis considers three components: the ego, the super ego and the id (or drives) [24]. The ego has been explained in the previous section. The super ego is supposed to be located in the prefrontal cortex where the person's moral and ethics, that is, the sense of right and wrong are located. Thoughts go from the unconscious (id or drives) to the pre-conscious (ego) and then back and forth to the conscious (super ego). This is because ideas flow from the unconscious to the pre-conscious, ending in the conscious (the latter related to matters of moral and ethics).

The id, on the other hand, is what is typically known as the unconscious. It is the storming sea of ideas flowing back and forth and changing from moment to moment. Only one of these unconscious thoughts becomes conscious and it is manifested as some specific idea that we can remember and forget at any given moment. The human mind has an internal clock operating every 200 milliseconds. That is, a given though can become conscious roughly every 200 milliseconds from the unconscious sea of the id.

What does cognitive neuroscience say about all this? Cognitive neuroscience and, more specifically, the Global Workspace Theory (GWT) indicates that the information flows from the unconscious (id or drives) to the pre-conscious (ego) and from that point onwards a feedback flow with the conscious (super ego) is generated [25]. This is illustrated in Figure 2.

\section{The Quantum Nature of the Human Mind}

But the truth is that we cannot choose what to think. Although, in principle, we can think anything, once some specific thought sets in our minds, we are no longer free to think anything else. In this regard, the brain is like some kind of 


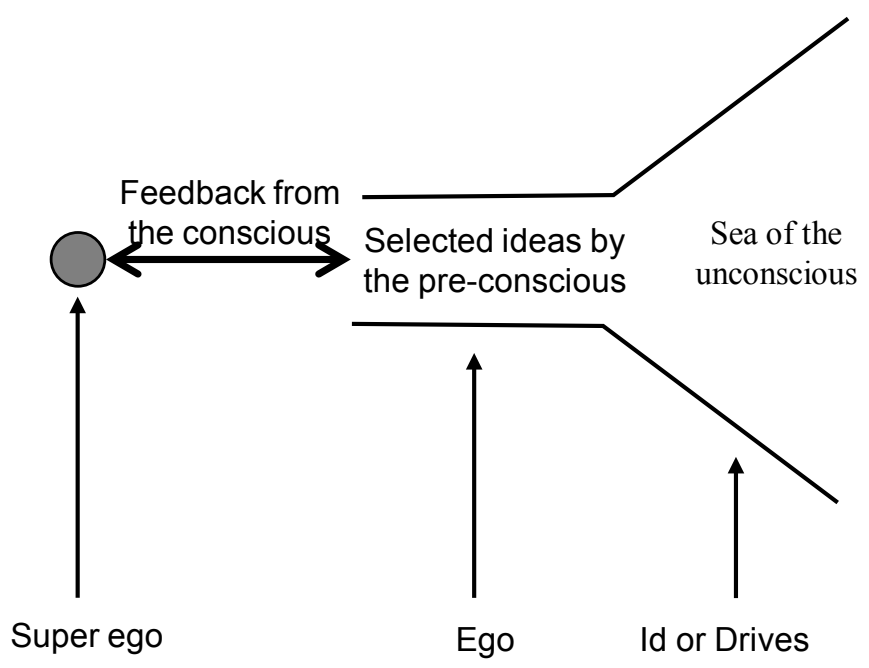

Figure 2. The three components of the human mind.

quantum computer, having results becoming manifested in a concrete way, that is, losing their quantum entanglement, every 200 milliseconds approximately.

Roger Penrose thinks that there is an inherent quantum nature required for the existence of consciousness [26]. He believes there are DNA related structures called microtubules that allow the brain to be a quantum computer. I believe that if we are to create a truly conscious machine (that is, strong AI), we will have to seamlessly combine the powers of a sufficiently large quantum computer with a powerful enough digital computer.

\section{The Universal Language of the Human Brain}

Is there a universal language for the human mind? That is, are the neuronal firing patterns of someone equivalent to another one? Experiments among righthanded people (that is, people whose dominating brain hemisphere is the left one, since the left hemisphere is connected to the right side of the body) have been conducted, in order to see if there is a universal neuronal language [27] [28]. Objects and the words for these substantive figures are shown to the people whose brain activity is being measured using a magnetic resonance imaging machine. Then, an artificial neural network is trained using machine learning to associate the brain activation patterns with the nouns being analyzed for the different subjects in the study. It has been discovered that it is possible to predict what it is someone is thinking by merely analyzing their neuronal brain patterns (metabolic activity), although such feat is limited to nouns only. Thus, it is highly likely there actually exists a universal brain language, even though trough the intervention of machines for neuronal firing pattern translations. This has incredible applications to paraplegic people, since it could allow them in a perhaps not so distant future to control external suits bringing them back the motor activity or even making them stronger than normal people. Alternatively, it could allow normal people to control at distance extremely complex robots, almost 
human-like, in terms of their motor skills.

\section{The Reality about Creating Strong Artificial Intelligence}

What about the possibility of creating an artificial machine with natural intelligence? Franklin has been speculating and elaborating conceptual models about such possibility [29]. By the end of the 1990s, Hans Moravec [30] calculated the number of basic operations per second of information processing carried out by a human brain based on visual information processing. His result: 100 million MIPS $^{1}$ per human brain. An operation per second is equivalent, in terms of digital computers, to do one basic binary operation per second, such as adding two binary numbers or transferring a binary number from one position in memory to another one. Moore's law empirically establishes that approximately every 18 months computer information processing doubles at the same cost per computer. Extrapolation based on past data have been carried out indicating that by the year 2030 there should be, according to Moore's law, a personal computer with the information processing capacity of the human brain. However, Moore's law has already reached its limits. It is no longer possible to build smaller electrical circuitry, also called micro transistor chips (and as a consequence faster, since light takes less time to travel from one place of the micro transistor to another one), by reducing by half the size of the micro transistor, due to problems inherent to the way in which such micro transistors are built (specifically, lithography). Truth is that approximately during the last decade the electronic industry has been cheating on us. We are getting all kinds of different applications of the same micro transistors in all sorts of devices (smaller laptops with different and ever more consuming memory and hard drive resources, pocket size cell phones, all different sorts of Internet-related applications, and even the promise of the so-called Internet of Things-IoT).

What has been achieved is the duplication of the information processing speed of the first personal computers from the 1960s and 1970s thirty times. That is, approximately, an information processing speed of $2^{30} \approx 1,000^{\prime} 000,000^{2}$ clock cycles of computer per second, also simply called Hertz (Hz). Thus, if every personal computer has an information processing speed of $1 \mathrm{GHz}$ $\left(1,000^{\prime} 000,000\right.$ operations per second), we would require $100^{\prime} 000,000^{\prime} 000,000$ information processing operations per second per human mind divided by $1,000^{\prime} 000,000$ operations per second or $\mathrm{Hz}$ of each artificial processor, that is, we would require an AI laboratory of 100'000,000'000,000/1,000'000,000 = 100,000 personal computers properly connected in some way (still somewhat unknown for the time being) in order to compute the amount of information processing carried out by one person. Even if we knew how to connect the machines appropriately, having 100,000 personal computers connected makes the work close to impossible. It is not feasible that normal AI laboratories around the world ${ }^{1}$ MIPS are Million Instructions per Second.

${ }^{2} 2^{10}=1024$, so that $2^{30}=1024 \times 1024 \times 1,024 \approx 1,000$ '000,000. The best modern micro processors today are not faster than $4 \mathrm{GHz}$ (Gigahertz or 4 thousand million Hertz). 
could properly connect 100,000 computers, not to mention buying all those computers, hosting them, and making the research affordable enough so that a lot of AI laboratories could carry out the same endeavor so that scientific exchanges could accelerate innovation pace.

We would require, at least, to double information processing speed 1000 times more (that is, $2^{40} \approx 1^{\prime} 000,000^{\prime} 000,000 \mathrm{~Hz}$ per microprocessor), so that the number of required computers could go down from 100,000 to 100 (or even 50 or 25, or maybe even just one if we allow for the consideration that human-designed digital information processing should be more efficient for not depending on evolution, having a lot of redundancies). This would make the required research work much more reasonable, affordable and likely to be carried out by enough AI laboratories in the world so that the scientific exchange of information and knowledge could trigger exponential design gains.

\section{Discussion and Conclusions}

$\mathrm{DARPA}^{3}$ is already researching other ways to approach the problem. Specifically, they are considering having a couple of antennas within nanometers in size (sizes close to the ones of molecules) and sending information between them. The key of the discovery is to have one of the antennas with a concave shape so that it can send focalized information to the other antenna. However, this work is highly experimental, not to mention the fact that we would need industrial processes able to mass produce this kind of electronic device. Thus, this work does not seem to be practical in the foreseeable future.

Another alternative is to integrate a quantum computer to a digital computer. Recently, IBM launched a 50 qubits quantum computer [31]. Google and other tech companies have announced efforts to increase the number of qubits. If it were possible to have a 256 qubits quantum computer that holds quantum entanglement for at least 200 milliseconds, it may be possible to integrate such quantum computer with a digital computer working also on 256 bits (one byte) in bandwidth. In this way, in a still unknown form, it may be possible to represent "thoughts" using sets of bytes (characters in the ASCII standard) and build something similar to what is seen in the trilogy "The Matrix", except that "the code" would be alphanumerical characters of one byte. Actually, we will probably have to wait for both things: a quantum computer having 256 qubits and digital computers as fast as $4 \mathrm{THz}$ ( 4 terahertz or 4’000,000'000,000 operations per second). The latter is due to my hypothesis that, just like Roger Penrose considers it, the functioning of the human brain depends both on quantum as well as digital computing processes, having an internal clock of approximately 200 milliseconds between quantum entanglement losses marking consecutive states of consciousness.

Thus, if we want to build several machines with natural intelligence, all we have left to do is to expect the required technology in quantum and digital ${ }^{3}$ DARPA is the Defense Advanced Research Projects Administration, and it is the advanced research arm of the Pentagon in the United States. 
computing to advanced enough in order to reach the minimum levels previously indicated, that is, quantum computers of 256 qubits having a minimum quantum entanglement lapse of 200 milliseconds (at a reasonable price, not greater than USD $\$ 10,000$ ) and digital computers at reasonable prices (around USD $\$ 1000$ per computer) with information processing speeds of $1 \mathrm{THz}$ to $4 \mathrm{THz}$ (100 THz would of course be the ideal). Consequently, the only technological alternative would be the creation of a single artificial machine with natural intelligence in the world. Such technological wonder could be achieved at this moment with the opportunity the creation of the $5 \mathrm{G}$ cell phone infrastructure around the world brings about. Since the infrastructure for such network would be, presumably, new, there is the possibility of creating the $5 \mathrm{G}$ network in such way that it can not only be used for the telecommunications of the future, but also for the infrastructure providing the technological hardware to create an artificial machine with natural intelligence working by being supported by such $5 \mathrm{G}$ network. Tononi [32] [33] [34] has developed an entire mathematical model concerning the kind of requirements such artificial consciousness would require and how it could operate.

The artificial machines with natural intelligence of the future will be, presumably, much more powerful and capable of much more complex thoughts than the ones a human mind could have. Consequently, a second of thinking of one of these machines would probably contain more information than an entire encyclopedia. Their senses would have a greater detail of resolution and as a consequence a wider bandwidth and since thoughts are built based on the senses they are constructed upon, their thoughts would be much more complex and capable of a wider bandwidth than a human being could have.

\section{Conflicts of Interest}

The author declares no conflicts of interest regarding the publication of this paper.

\section{References}

[1] Varela, F.J., Thompson, E. and Rosch, E. (1993) The Embodied Mind: Cognitive Science and Human Experience. The MIT Press.

[2] Kurzweil, R. (2013) How to Create a Mind: The Secret of Thought Revealed. Penguin Books.

[3] Damasio, A. (2011) The Quest to Understand Consciousness. TED Talks. https://www.ted.com/talks/antonio_damasio_the_quest_to_understand_consciousnes

[4] Adolphs, R., Gosselin, F., Buchanan, T.W., Tranel, D., Schyns, P. and Damasio, A.R. (2005) A Mechanism for Impaired Fear Recognition after Amygdala Damage. Nature, 433, 68-72. https://doi.org/10.1038/nature03086

[5] Tranel, D., Adolphs, R., Damasio, H. and Damasio, A.R. (2001) A Neural Basis for the Retrieval of Words for Actions. Cognitive Neuropsychology, 18, 655-670. https://doi.org/10.1080/02643290126377

[6] Damasio, A. and Meyer, K. (2008) Behind the Looking-Glass. Nature, 454, 167-168. 
https://doi.org/10.1038/454167a

[7] Koenigs, M., Young, L., Adolphs, R., Tranel, D., Cushman, F., Hauser, M. and Damasio, A. (2007) Damage to the Prefrontal Cortex Increases Utilitarian Moral Judgments. Nature, 446, 908-911. https://doi.org/10.1038/nature05631

[8] Damasio, A. (2001) Fundamental Feelings. Nature, 413, 781. https://doi.org/10.1038/35101669

[9] Anderson, S.W., Bechara, A., Damasio, H., Tranel, D. and Damasio, A.R. (1999) Impairment of Social and Moral Behavior Related to Early Damage in Human Prefrontal Cortex. Nature Neuroscience, 2, 1032-1037. https://doi.org/10.1038/14833

[10] Khalsa, S., Rudrauf, D., Damasio, A.R., Davidson, R.J., Lutz, A. and Tranel, D. (2008) Interoceptive Awareness in Experienced Meditators. Psychophysiology, 45, 671-677. https://doi.org/10.1111/j.1469-8986.2008.00666.x

[11] Shiv, B., Loewenstein, G., Bechara, A., Damasio, H. and Damasio, A.R. (2005) Investment Behavior and the Negative Side of Emotion. Psychological Science, 16, 435-439.

[12] Anderson, S.W., Damasio, H., Tranel, D. and Damasio, A.R. (2000) Long-Term Sequelae of Prefrontal Cortex Damage Acquired in Early Childhood. Developmental Neuropsychology, 18, 281-296. https://doi.org/10.1207/S1532694202Anderson

[13] Habibi, A. and Damasio, A. (2014) Music, Feelings, and the Human Brain. Psychomusicology: Music, Mind, and Brain, 24, 92-102. https://doi.org/10.1037/pmu0000033

[14] Damasio, A. (2007) Neuroscience and Ethics: Intersections. The American Journal of Bioethics, 7, 3-7. https://doi.org/10.1080/15265160601063910

[15] Meyer, K., Kaphan, J.T., Essex, R., Webber, C., Damasio, H. and Damasio, A. (2010) Predicting Visual Stimuli on the Basis of Activity in Auditory Cortices. Nature Neuroscience, 13, 667-668. https://doi.org/10.1038/nn.2533

[16] Adolphs, R., Tranel, D., Koenigs, M. and Damasio, A.R. (2005) Preferring One Taste over Another without Recognizing Either. Nature Neuroscience, 8, 860-861. https://doi.org/10.1038/nn1489

[17] Philippi, C.L., Feinstein, J.S., Khalsa, S.S., Damasio, A., Tranel, D., Landini, G., Wiliford, K. and Rudrauf, D. (2012) Preserved Self-Awareness Following Extensive Bilateral Brain Damage to the Insula, Anterior Cingulate, and Medial Prefrontal Cortices. PLoS ONE, 7, e38413. https://doi.org/10.1371/journal.pone.0038413

[18] Kawasaki, H., Adolphs, R., Kaufman, O., Damasio, H., Damasio, A.R., Granner, M., Bakken, H., Hori, T. and Howard III, M.A. (2001) Single-Neuron Responses to Emotional Visual Stimuli Recorded in Human Ventral Prefrontal Cortex. Nature Neuroscience, 4, 15-16. https://doi.org/10.1038/82850

[19] Damasio, A.R., Grabowski, T.J., Bechara, A., Damasio, H., Ponto, L.L.B., Parvizi, J. and Hichwa, R.D. (2000) Subcortical and Cortical Brain Activity during the Feeling of Self-Generated Emotions. Nature Neuroscience, 3, 1049-1056. https://doi.org/10.1038/79871

[20] Adolphs, R., Tranel, D. and Damasio, A.R. (1998) The Human Amygdala in Social Judgment. Nature, 393, 470-474. https://doi.org/10.1038/30982

[21] Damasio, A. and Carvalho, G.B. (2013) The Nature of Feelings: Evolutionary and Neurobiological Origins. Nature Reviews. Neuroscience, 14, 143-152. https://doi.org/10.1038/nrn3403

[22] Preston, S.D., Bechara, A., Damasio, H., Grabowski, T.J., Stansfield, R.B., Mehta, S. and Damasio, A.R. (2007) The Neural Substrates of Cognitive Empathy. Social 
Neuroscience, 2, 254-275. https://doi.org/10.1080/17470910701376902

[23] Damasio, A. (2003) The Person Within. Nature, 423, 227. https://doi.org/10.1038/423227a

[24] Langs, R. (2010) Freud on a Precipice: How Freud's Fate Pushed Psychoanalysis over the Edge. Jason Aronson.

[25] Baars, B.J. and Cage, N.M. (2010) Cognition, Brain, and Consciousness: Introduction to Cognitive Neuroscience. Academic Press, Cambridge.

[26] Penrose, R. (1997) The Large, the Small and the Human Mind. Cambridge University Press, Cambridge.

[27] Just, M.A., Cherkassky, V.L., Aryal, S. and Mitchell, T.M. (2010) A Neurosemantic Theory of Concrete Noun Representation Based on the Underlying Brain Codes. PLoS ONE, 5, e8622. https://doi.org/10.1371/journal.pone.0008622

[28] Shinkareva, S.V., Mason, R.A., Malave, V.L., Wang, W., Mitchell, T.M. and Just, M.A. (2008) Using fMRI Brain Activation to Identify Cognitive States Associated with Perception of Tools and Dwellings. PLoS ONE, 3, e1394. https://doi.org/10.1371/journal.pone.0001394

[29] Franklin, S. (2001) Artificial Minds. The MIT Press, Cambridge.

[30] Moravec, H. (1999) Robot: Mere Machine to Transcendent Mind. Oxford University Press, Oxford.

[31] Knight, W. (2019) IBM Raises the Bar with a 50-QuBit Quantum Computer. https://www.technologyreview.com/s/609451/ibm-raises-the-bar-with-a-50-qubit-q uantum-computer/

[32] Tononi, G. and Edelman, G.M. (1998) Consciousness and Complexity. Science, 282, 1846-1851. https://doi.org/10.1126/science.282.5395.1846

[33] Tononi, G. (2008) Consciousness as Integrated Information: A Provisional Manifesto. Biological Bulletin, 215, 216-242. https://doi.org/10.2307/25470707

[34] Tononi, G. (2012) Integrated Information Theory of Consciousness: An Updated Account. Achives Italiennes de Biologie, 150, 56-90. 